\title{
Study on Permeability of Soil-Rock Mixture in Water-Blocking Layer of Open-Pit Coal Mine Dump Site
}

\author{
Boyu Luan $\mathbb{D}^{1,2}$ Wei Zhou ${ }^{1 D},{ }^{1,2}$ Xin Meng, ${ }^{2}$ Xiang Lu $\mathbb{D}^{2}{ }^{2}$ and Zhichao Liu ${ }^{3}$ \\ ${ }^{1}$ State Key Laboratory of Coal Resources and Safe Mining, China University of Mining \& Technology, Xuzhou, \\ Jiangsu 221116, China \\ ${ }^{2}$ School of Mines, China University of Mining and Technology, Xuzhou, Jiangsu 221116, China \\ ${ }^{3}$ Heidaigou Open-Pit Coal Mine, Shenhua Group Zhungeer Energy Co., Ltd., Zhungeer 010300, China \\ Correspondence should be addressed to Wei Zhou; loutian1982@126.com
}

Received 15 December 2019; Revised 13 August 2020; Accepted 11 September 2020; Published 23 September 2020

Academic Editor: Hui Yao

Copyright (c) 2020 Boyu Luan et al. This is an open access article distributed under the Creative Commons Attribution License, which permits unrestricted use, distribution, and reproduction in any medium, provided the original work is properly cited.

\begin{abstract}
Constructing a water-blocking layer in the dump sites of an open-pit coal mine is of great significance to improve the water retention capacity of the reclamation area. The permeability law of the water-blocking layer is costly to be analyzed and researched by means of field tests. In this study, the soil-rock mixture samples similar to the water-blocking layer were prepared, and the rock block proportion (RBP) and hydraulic pressure were adopted as test variables to conduct a permeability test, which provided theoretical support for on-site construction. The results show that when the hydraulic pressure is less than the confining pressure, the permeability increases at a steady rate as the rock block proportion increases. When the hydraulic pressure is close to or equal to the confining pressure, penetrating cracks are easily formed between the soil-rock interfaces of the sample with a higher rock block proportion, resulting in a rapid increase in permeability. With the increase of hydraulic pressure, the migration of the internal fine particles in the sample with a rock block proportion of $40 \%$ or less leads to the partial cracks closure, which gradually reduces the permeability. The internal structure of the sample with a rock block proportion more than $40 \%$ experiences a process in which the permeability decreases with the crack closure to a significant increase due to the penetrating crack formation. In summary, the soil-rock mixture with about $30 \%$ rock block proportion is characterized by suitable permeability and stability, which guarantees the construction cost on-site at the same time. In addition, increasing the rolling times of the truck can increase the compaction of the water-blocking layer and reduce the permeability. The roughness and gradation of the rock blocks can improve the permeability and stability of the water-blocking layer.
\end{abstract}

\section{Introduction}

The new open-pit coal mine reclamation process in China divides the topsoil adopted for ecological restoration from top to bottom into humus, aquifers, and water-blocking layer, as shown in Figure 1. The permeability of the waterblocking layer directly affects the soil and root environment required for plant growth [1-3]. The current process adopts compacted clay mined in open-pit coal mines as waterblocking layer. However, as shown in Figure 2, the waterblocking layer is facing the problem of rock inclusion. This material is called a soil-rock mixture. It is of practical significance to study variables such as rock block proportions and thickness of water-blocking layer on permeability through an on-site test, but the economic and time costs are high. Therefore, a rough prediction of the on-site test results can be obtained through the laboratory tests of the soil-rock mixture, which can guide the on-site test design.

Soil-rock mixture exists in many natural geological and artificial civil engineering projects [4-6]. Because of its different existence conditions and compositions [7, 8], many scholars have different research methods and focuses on soil-rock mixtures under different engineering backgrounds. Ding [9] aimed at the soil-rock mixture in the dump site of an open-pit coal mine. Based on the CT images of the samples, numerical models of different rock block proportions and porosity were established for penetration simulation experiments. The result shows that increasing the 


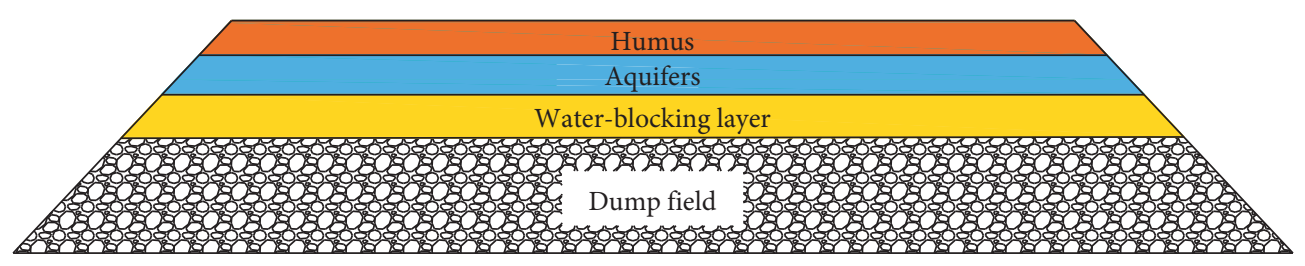

Figure 1: Distribution of reclamation strata in the dump sites.

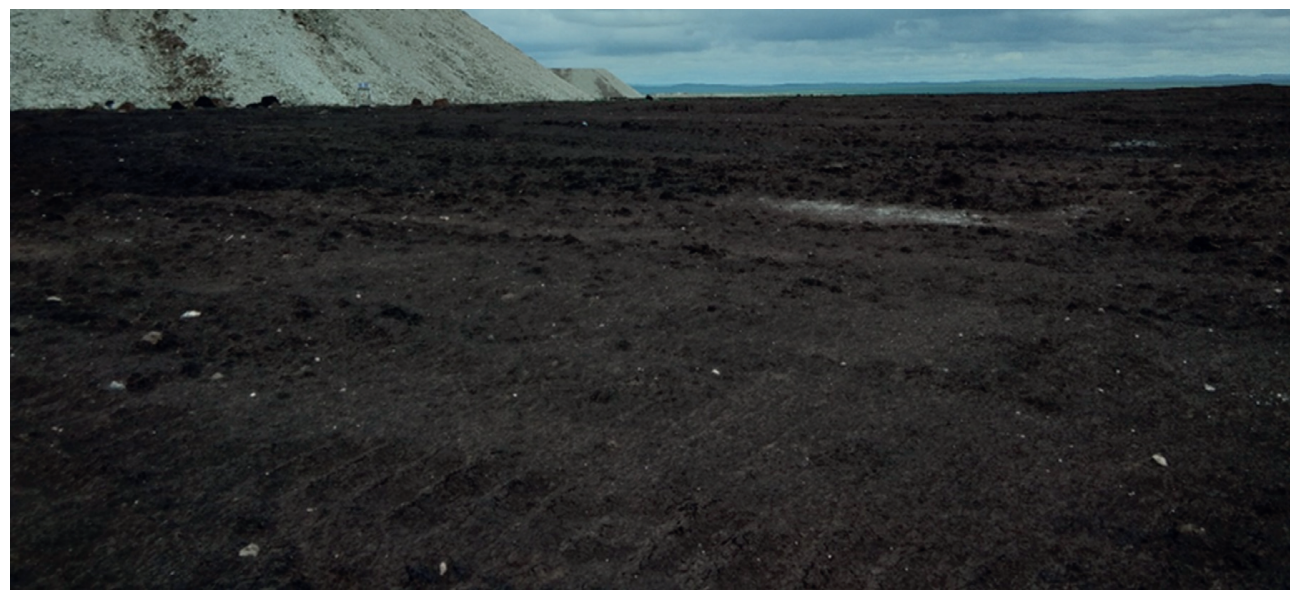

FIGURE 2: Water-blocking layer.

rock block proportion and compaction rate of the soil-rock mixture can improve the water retention capacity of the water-blocking layer. Zhao [10] established a numerical model consisting of soil, rocks, and water to reveal the water inrush mechanism of a fault tunnel and simulated the migration of water at different initial and dynamic velocities. Both of them are studied by numerical simulation. The advantage is that the seepage inside the soil-rock mixture can be clearly observed, but the research on the contact model of the soil-rock interface is not yet mature, so the correctness of some conclusions cannot be determined.

Zhou et al. [11] improved the existing soil-rock mixture seepage model. The improved model considered the influence of voids and fine particles on permeability, and they verified the accuracy of the model based on the experimental results. In [12], in order to solve the problem that the compacted clay that acts as a water-blocking layer in the landfill is prone to dry and crack in a dry environment, the hydraulic conductivity of sand-clay mixtures, threshold gradient, and bound forms of pore water were studied. The results show that changing the sand content of the soil can change the effective pore size of the soil. Wang [13] studied the compressibility and permeability characteristics of sandstone-mudstone mixtures. It shows that the compaction degree of soil-rock mixture is positively correlated with permeability. Wang [14] studied the porosity and particle damage of the compacted soil-rock mixture during the vibration compaction test. The results show that proper particle size distribution can effectively fill the voids between the framework particles and reduce the porosity. These researches related to the relationship between voids and permeability through laboratory experiments show that the internal structure of the soil-rock mixture has a strong correlation with permeability, and it is also an important idea for studying the cause of permeability change in this paper.

The construction of the water-blocking layer of open-pit coal mines in China has only been proposed in recent years, so there is currently little research on the water-blocking layer of open-pit coal mine dump sites. This study simulated the environment of the water-blocking layer to prepare soilrock mixture samples and tested the effects of rock block proportion and hydraulic pressure on permeability. By comparing with other scholars' researches, the analysis carried out from materials and microstructure draws the conclusions which are beneficial to ensure a balance between permeability and construction difficulty.

\section{Materials and Methods}

2.1. Samples Preparation. In the context of water-blocking layer of open-pit coal mine dump site, clay, a by-product produced during the coal mining process, contains rocks of different sizes and shapes mixed in it, which is impossible to avoid. In order to simulate the similar engineering situation, the clay $(0 \sim 1 \mathrm{~mm})$ collected on-site and sandstone were adopted to prepare soil-rock mixture samples. The materials are dried with a drying box before sample preparation. Sandstone shown in Figure 3 is sieved by using $1 \sim 2 \mathrm{~mm}$, $2 \sim 5 \mathrm{~mm}, 5 \sim 8 \mathrm{~mm}$, and $8 \sim 10 \mathrm{~mm}$ classifying sieves. A certain amount of water will be mixed with the dried clay, so that the moisture content is $20 \%$.

The test set contains four kinds of samples with rock block proportions (weight proportions) of 30\%, 40\%, 50\%, 


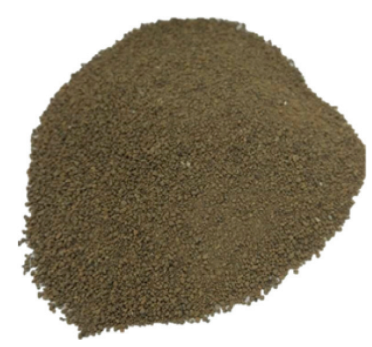

(a)

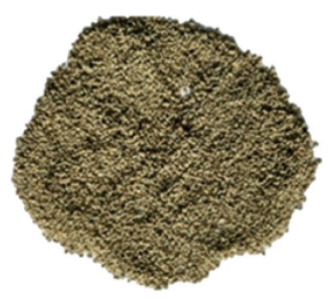

(b)

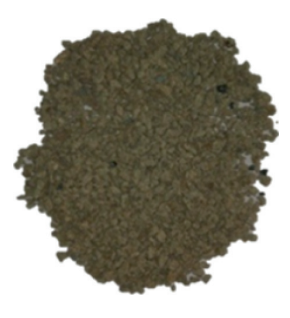

(c)

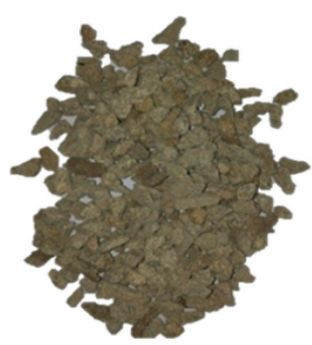

(d)

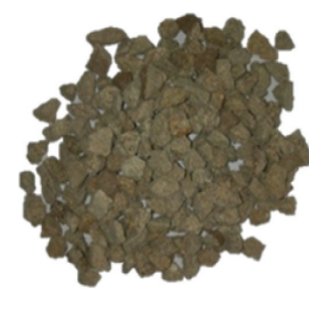

(e)

Figure 3: Sieved soil and sandstone: (a) $0 \sim 1 \mathrm{~mm}$; (b) $1 \sim 2 \mathrm{~mm}$; (c) $2 \sim 5 \mathrm{~mm}$; (d) $5 \sim 8 \mathrm{~mm}$; (e) $8 \sim 10 \mathrm{~mm}$.

and 60\% (the samples are called A30, A40, A50, and A60 in this paper). Considering that the compaction of the waterblocking layer is carried out by repeated rollings of the truck, the compaction method of the samples was chosen to adopt a consolidometer to compact all the samples under the same conditions. According to the results of Wan-Jun [15], $400 \mathrm{kPa}$ pressure was adopted to simulate the compaction process of the clay water-blocking layer in an open-pit coal mine with 48 hours consolidation time. The graded soil-rock mixtures (the particle gradation is shown in Figure 4) were filled into a consolidometer for drainage consolidation. According to experience, the quality of each filling is about $460 \mathrm{~g}$, which can ensure that every consolidated sample is basically a $50^{*} 100 \mathrm{~mm}$ sample. The sample preparation process is shown in Figure 5.

2.2. Permeability Test. For the permeability test equipment, the British GDS triaxial test machine shown in Figure 6 was adopted. This machine provides confining pressure through water pressure. The principle of the permeability test is that when the seepage velocity measured by the two seepage sensors above and below the sample should be consistent, and the seepage velocity is the permeability. The structural diagram is shown in Figure 7.

Permeability test process is conducted as follows: (1) Install the sample wrapped with rubber film and permeable stone into the testing machine to ensure the tightness of the sample. (2) Fill the cell pressure chamber with water, pay attention to the change in permeability, ensuring the sample is still sealed. (3) Apply $50 \mathrm{~N}$ axial pressure to ensure close contact between the sample and the machine. (4) Apply a $300 \mathrm{kPa}$ confining pressure, and then conduct the permeability test.

Each sample with different rock block proportions was tested for permeability at $100 \mathrm{kPa}, 150 \mathrm{kPa}, 200 \mathrm{kPa}, 250 \mathrm{kPa}$, and $300 \mathrm{kPa}$ hydraulic pressures. The hydraulic pressure $(P)=$ back pressure-base pressure. And the base pressure was set to 0 .

\section{Results and Discussion}

Rock block proportion and hydraulic pressure are the two common variables to study the permeability of soil-rock mixtures [16-18]. At the same time, these two variables are with good engineering significance in this study:

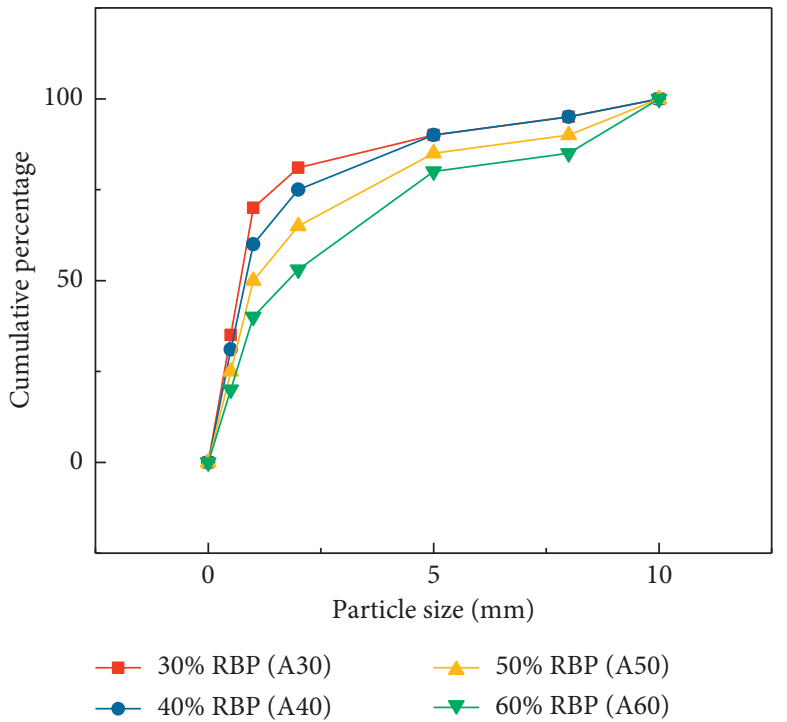

Figure 4: Particle gradation of soil-rock mixture.

(1) Rock block proportion: the clay in the waterblocking layer is excavated by using an excavator in the open-pit mining area without blasting. Therefore, the rock block proportion of the clay obtained by excavation can be reduced through a more detailed excavation process, such as using a small bucket capacity excavator or a frontloader.

(2) Hydraulic pressure: the purpose of the waterblocking layer construction is to ensure that the water required for plant growth is not easy to lose. Therefore, hydraulic erosion is one of the main sources of damage. Because the compaction degree and uniformity in the on-site field must be lower than those in the laboratory samples under the same compaction strength, a relatively large hydraulic pressure was selected to observe the change of permeability, which can predict the damage of the water-blocking layer on-site.

3.1. Rock Block Proportion Influence on Permeability. From the test results reflected in Figure 8, the soil-rock mixtures with different rock block proportions have a positive correlation with the permeability. The analysis and comparison with related tests or simulations are as follows: 


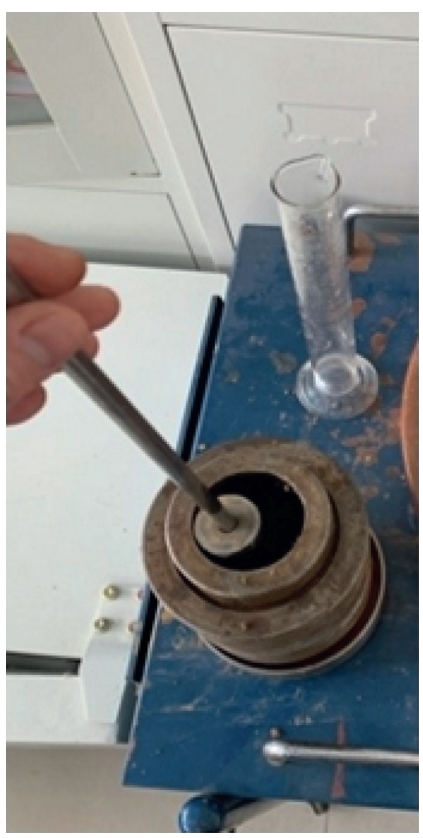

(a)

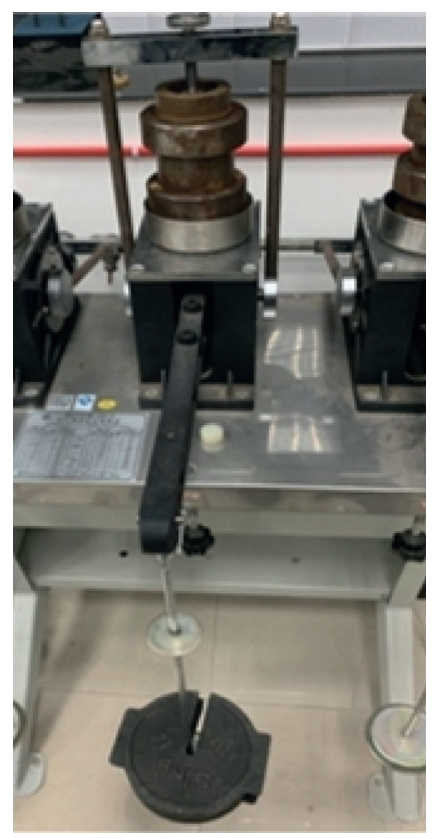

(b)

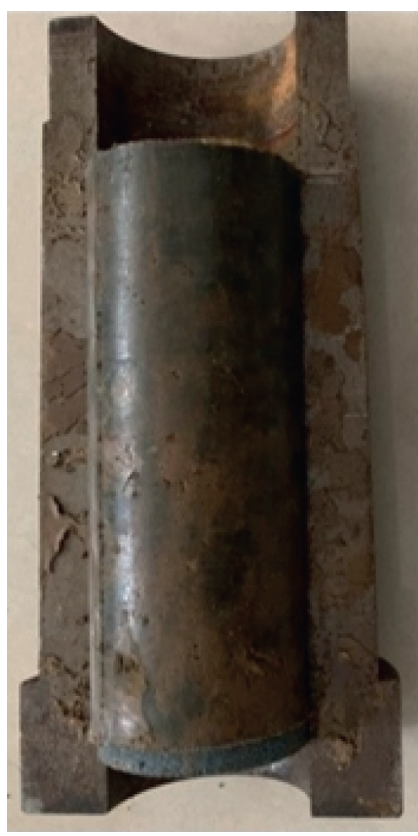

(c)

Figure 5: Sample preparation process with consolidometer. (a) Filling. (b) Compacting. (c) Removing the sample.

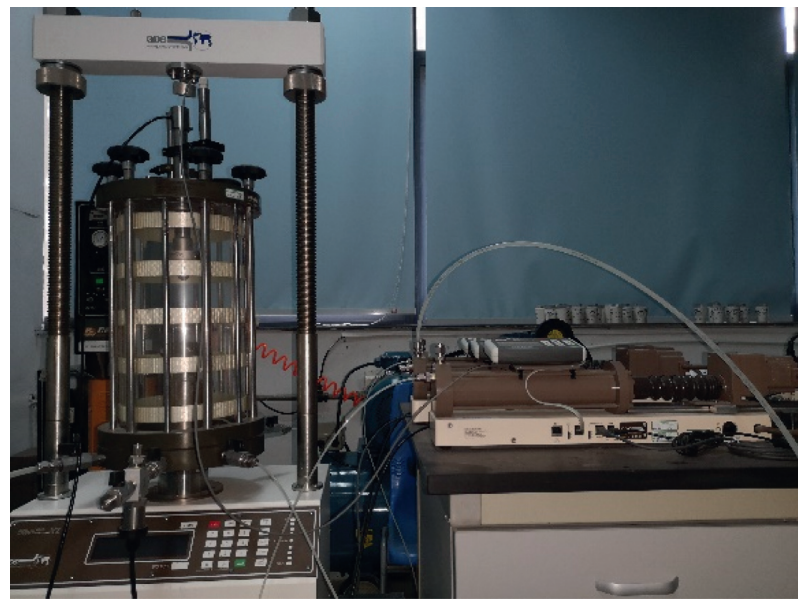

Figure 6: GDS triaxial test machine.

(1) The numerical simulation of Chen [19] and Xu [20] only considered the two phases (soil and rock). Ding [9] considered the three phases (soil, rock, and pores) but could not achieve the expansion of cracks under the influence of simulation principles. The soil-rock interface is the main factor that affects the permeability of the soil-rock mixture. Under hydraulic pressure, the soil-rock interface is prone to cracks leading to the increase in permeability. The simulation process did not reflect the dynamic change of the porosity inside the sample. Therefore, the simulated permeability depends on the weighted average permeability of rock and soil. In fact, the higher rock block proportion increases the area of the soil-rock interface and porosity, thus leading to the increase in permeability. In this study, uniform compaction conditions were carried out for all samples, so the rock block proportion and the compaction degree were negatively correlated, which further increased the permeability [13].

(2) From Figures $8(\mathrm{a}), 8(\mathrm{~b})$, and $8(\mathrm{c})$, the signs of the inflection point can be seen slightly at the position with a $40 \%$ rock block proportion. When the hydraulic pressure is equal to the confining pressure, from Figure 8(e), the sudden change in permeability at the $40 \%$ rock block proportion position can be clearly seen. In Wang's study [16], the $40 \%$ rock block proportion point was the point corresponding to the minimum permeability. In Chen's study [21], a curve similar to that of Figure 8(e) was obtained. It shows that $40 \%$ rock block proportion is a key point for the internal structure of soil-rock mixture. Based on the results from Figure 8, on the one hand, when the hydraulic pressure is less than the confining pressure, the confining pressure performs a strong hindrance to hydraulic damage and hinders the crack development. With the increase of the rock block proportion, the soil-rock interface increases, and the permeability maintains a steady growth rate. On the other hand, when the hydraulic pressure is close to or equal to the confining pressure, the protective effect of confining pressure becomes weaker, and cracks begin to develop. As shown in Figures $8(\mathrm{~d})$ and $8(\mathrm{e})$, when the rock block proportion exceeds a certain limit (Figure $8(\mathrm{~d})$ : $P=250 \mathrm{kPa}, \mathrm{RBP}=50 \%$; Figure $8(\mathrm{e}): P=300 \mathrm{kPa}$, $\mathrm{RBP}=40 \%$ ), the distance between the rocks is shortened, and soil-rock interfaces are prone to form 


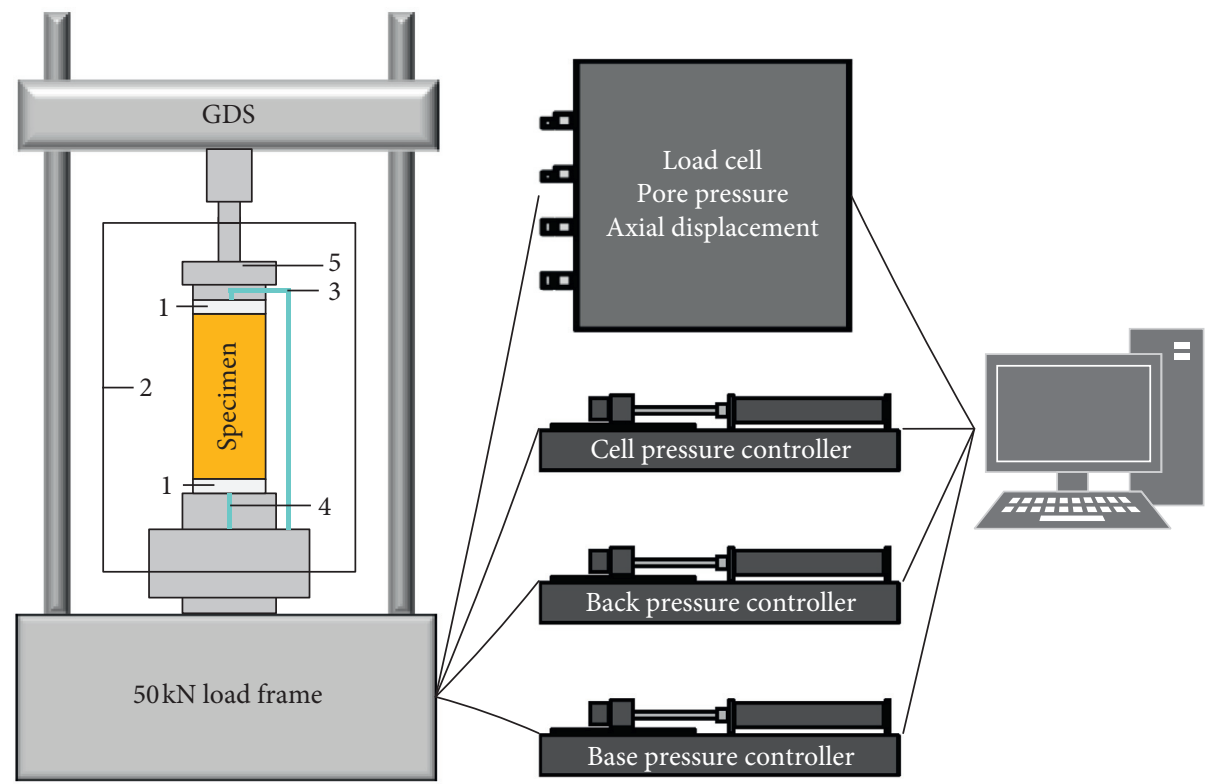

FIGURE 7: GDS structural diagram. (1) Permeable stone with filter paper; (2) cell pressure chamber; (3) back pressure; (4) base pressure; (5) axial force.

penetrating cracks, resulting in a significant increase in permeability. At this time, the rock itself becomes the main factor affecting the internal structure. In addition to the influence of rocks, the decrease in the proportion of clay which plays a dominant role in the water-blocking layer also leads to the permeability increases.

To sum up, first, during the construction of the waterblocking layer, the rolling times of the truck should be increased to improve the compaction. Second, no more than $30 \%$ rock block proportion on-site can better avoid the increase in permeability caused by the increase in hydraulic pressure. At the same time, a certain rock block proportion for engineering can effectively reduce the construction costs.

\subsection{Influence of Hydraulic Pressure on Permeability. As} shown in Figure 9, with the increase of hydraulic pressure, the permeability of the A30 and A40 samples gradually decreased, and in the permeability curves of the A50 and A60 samples, an inflection point appeared. The A30 sample permeability under different hydraulic pressures varies between $1.28 \times 10^{-6} \mathrm{~cm} / \mathrm{s}$ and $3.83 \times 10^{-6} \mathrm{~cm} / \mathrm{s}$, with a variance of 0.9 , which is less affected by the hydraulic pressure. The A60 sample permeability varies from $8.98 \times 10^{-6} \mathrm{~cm} / \mathrm{s}$ to $13.5 \times 10^{-6} \mathrm{~cm} / \mathrm{s}$ with the variance of 2.4 , which is greatly affected by the hydraulic pressure. A detailed analysis is given follows:

(1) Combined with the analysis in Section 3.1, and according to Ma [22], the penetration of soil-rock mixture samples is the process that the fine particles migrate with water to rebalance. Because the top and bottom of the sample are blocked by permeable stone in this study, the fine soil particles cannot migrate out of the sample with hydraulic erosion. Therefore, when the rock block proportion is less than or equal to $40 \%$, the fine particles migrate from top to bottom under the hydraulic pressure. Part of the soil cracks closes, and the cracks at the soil-rock interface slightly develop. Overall, the permeability decreases. When the rock block proportion reaches $50 \%$, the soil-rock interface increases. As the hydraulic pressure increases, firstly, the sample permeability decreases with further compaction caused by the particle migration process. Then, as the hydraulic pressure approaches the confining pressure, the internal structure is damaged with a penetrating crack developing between the soil-rock interface, leading to a significant increase in permeability. The schematic diagram is shown in Figure 10.

(2) One of the reasons that the soil-rock interface is the weak face of the soil-rock mixture is that the fine particles and the surface of the rock blocks do not fit well due to the fractal shape, resulting in larger pores. Wang's study [16] also adopted clay, but the permeability obtained was relatively large. In addition to confining pressure, the difference in rock blocks also caused the result. Figure 11 shows the rock block adopted in this paper and Wang's study. The simple parameter comparison of the two rock blocks are shown in Table 1 . The simple parameter comparison of the two rock blocks are shown in Table 1. Wang's study adopted marble, which has the characteristics of smooth movement during measurement without a sense of stagnation. The sandstone surface used in this study is relatively rough.

As the most vulnerable part of the internal structure of the soil-rock mixture, the cracks affect the resistance to hydraulic pressure. According to Wang's research [14] on 


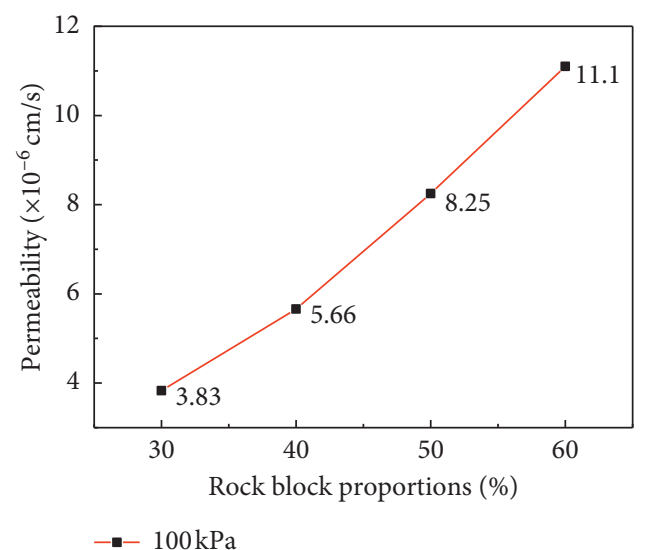

(a)

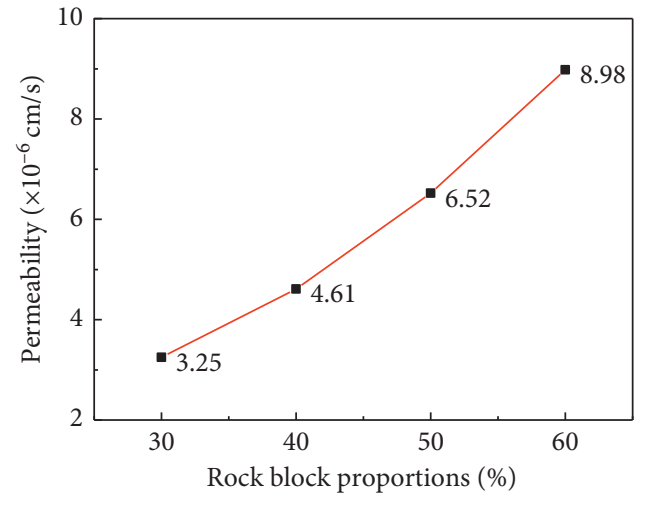

$--200 \mathrm{kPa}$

(c)

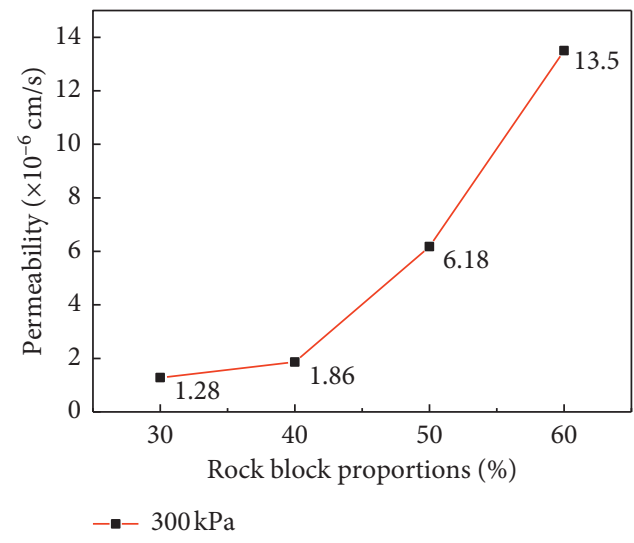

(e)

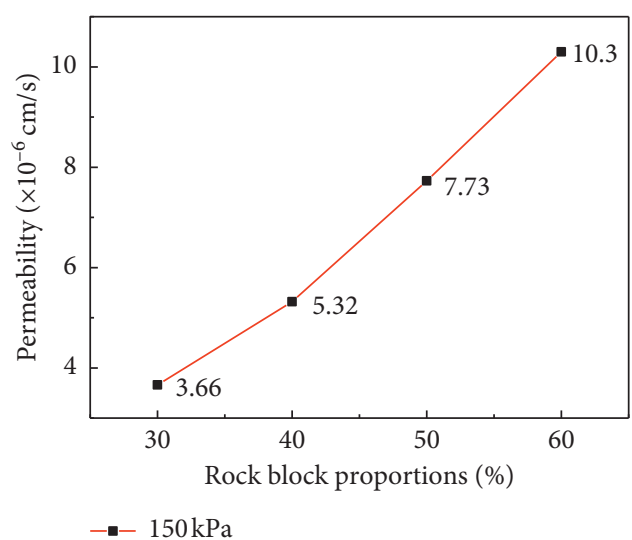

(b)

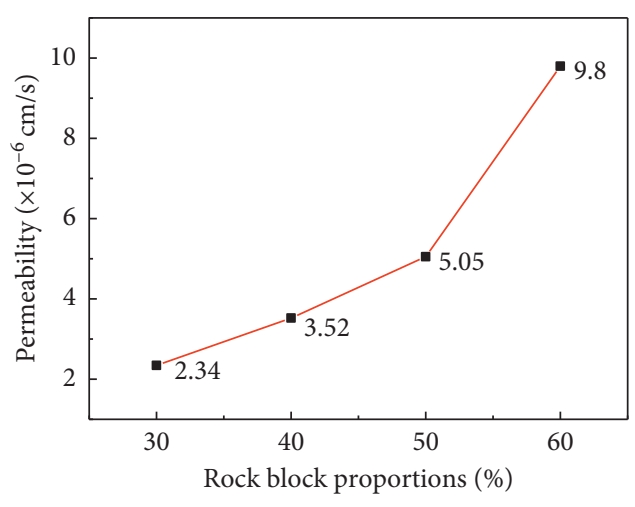

$-250 \mathrm{kPa}$

(d)

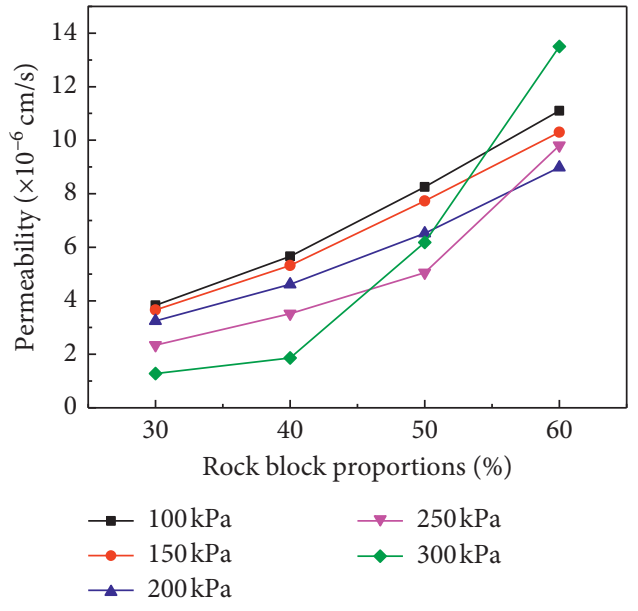

(f)

Figure 8: Variation curve of rock block proportion and permeability. (a) $P=100 \mathrm{kPa}$; (b) $P=150 \mathrm{kPa}$; (c) $P=200 \mathrm{kPa}$; (d) $P=250 \mathrm{kPa}$; (e) $P=300 \mathrm{kPa}$; (f) summary.

the compaction of soil-rock mixtures with different particle sizes, the size distribution of rock blocks adopted in this paper is wider, and it is more possible to form an excellent gradation similar to sand and stone in concrete, forming the most dense state with minimum porosity.

At the same time, the relatively rough surface of the rock blocks increases the friction between the materials and reduces the effect of hydraulic pressure, making the soil-rock interface difficult to be damaged and finally improving the stability of the internal structure.

Similar to test conditions, the water-blocking layer is laid above the dump site which acts like a permeable stone hindering the migration of fine-grained clay. The following conclusions can be made from the analysis: (1) Hydraulic 


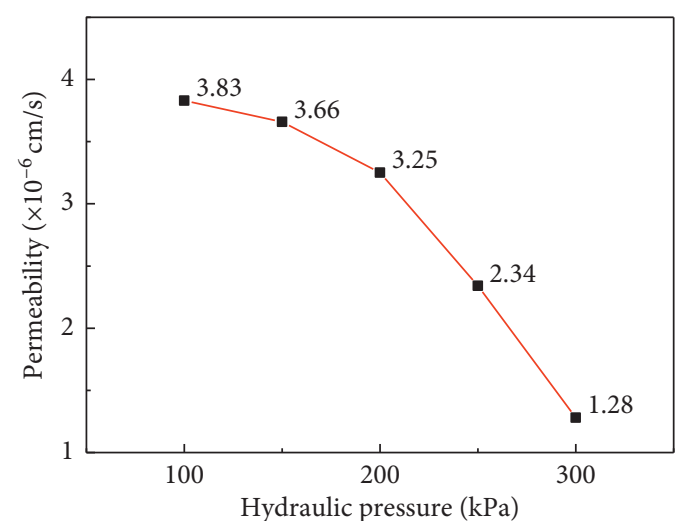

$-30 \%$ RBP

(a)

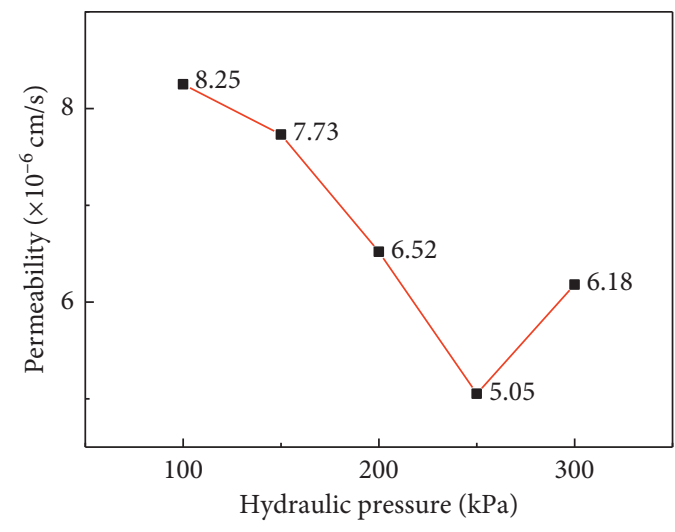

$--50 \% \mathrm{RBP}$

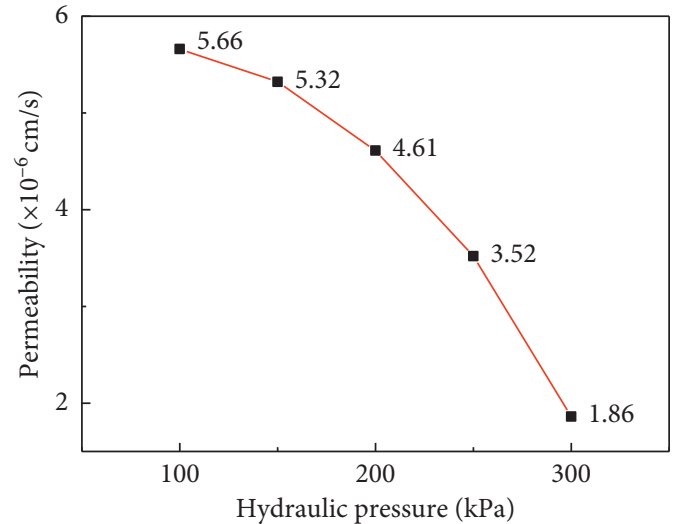

$-40 \% \operatorname{RBP}$

(b)

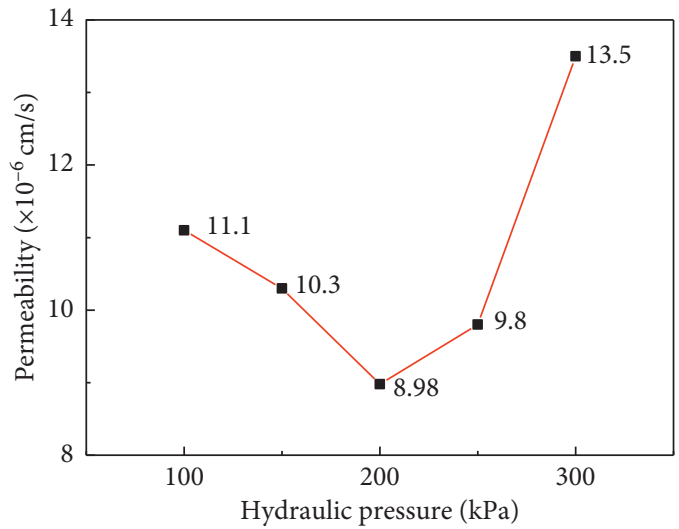

$-60 \% \mathrm{RBP}$

(c)

(d)

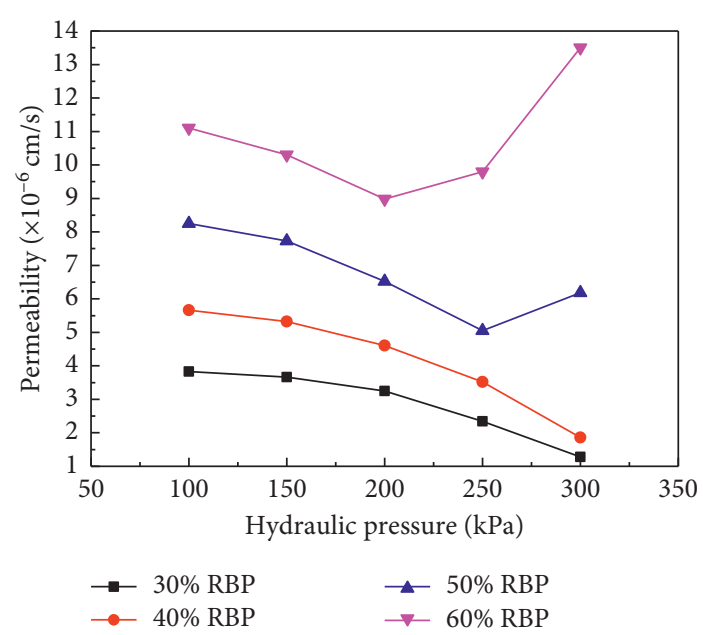

(e)

FIGURE 9: Curve of hydraulic pressure and permeability of soil-rock mixtures: (a) RBP $=30 \%$; (b) RBP $=40 \%$; (c) RBP $=50 \%$; (d) RBP $=60 \%$; (e) summary.

pressure changes the internal structure through the migration of fine particles in the soil-rock mixture. The 30\% rock block proportion can better prevent the formation of penetrating crack with the increase of hydraulic pressure. (2) The roughness and gradation of rock blocks affect the permeability and stability of the water-blocking layer. 


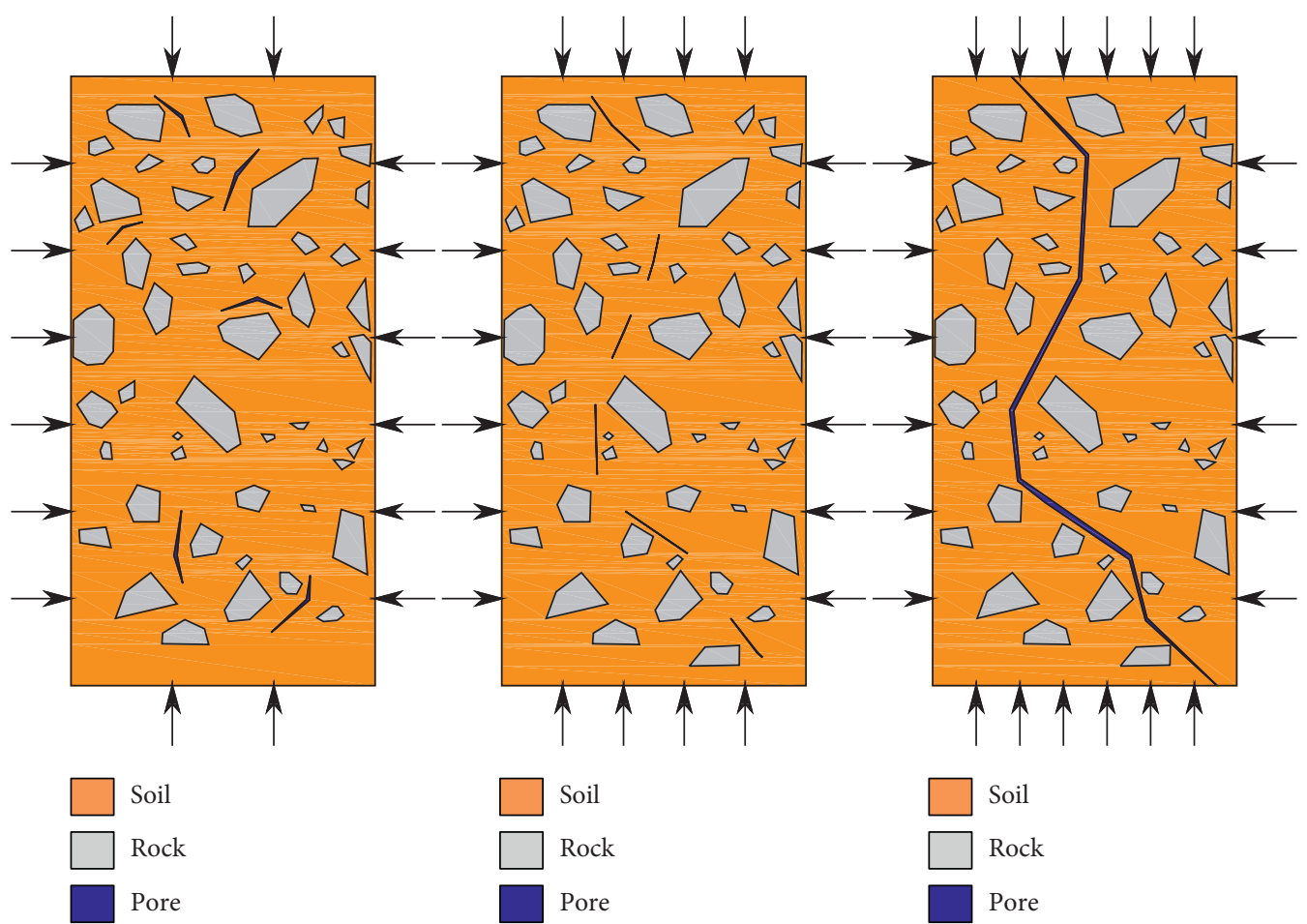

(a)

(b)

(c)

FIGURE 10: Schematic diagram of internal structure failure $(\mathrm{RBP}=50 \%)$ : (a) initial; (b) compacted; (c) penetrating crack formation.

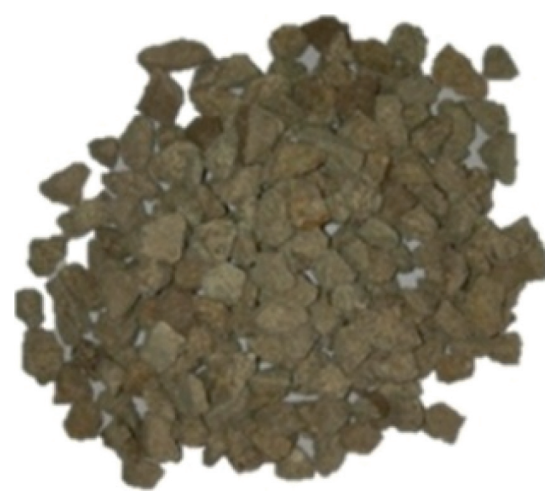

(a)

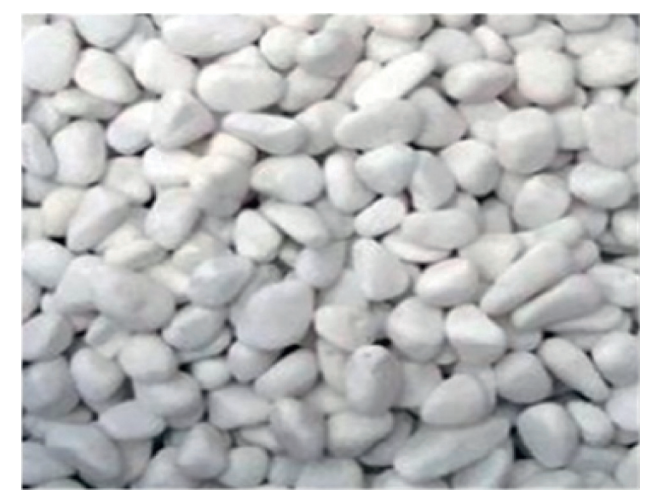

(b)

Figure 11: Rock blocks comparison: (a) this study; (b) Wang's study.

TABle 1: Comparison of rock block parameters.

\begin{tabular}{lccc}
\hline Rock block & Size $(\mathrm{mm})$ & Type & Surface \\
\hline Current study & $1-10$ & Sandstone & Rough \\
Wang's study & $2-5$ & Marble & Smooth \\
\hline
\end{tabular}

\section{Conclusions}

In this study, the soil-rock mixture samples with conditions similar to the water-blocking layer of an open-pit coal mine were prepared to conduct permeability tests to study the permeability under different rock block proportions and hydraulic pressure. The following conclusions are drawn from this study:
(1) Under the method of compaction by the truck, the rock block proportions will reduce the degree of compaction and increase the permeability. Therefore, during the construction of the water-blocking layer, the number of rolling times of the truck should be increased as much as possible to improve the compaction.

(2) With the increase of rock block proportions, the shortening of the distance between rock blocks makes it easy to form penetrating cracks at the soilrock interface, resulting in a great increase in permeability.

(3) The migration of fine particles under hydraulic pressure changes the internal structure of the soil- 
rock mixture. With the increase of hydraulic pressure, the internal structure of the sample with a rock block proportion more than $40 \%$ experienced a process in which the permeability decreases with the crack closure to a significant increase due to the penetrating crack formation.

(4) The soil-rock mixture with no more than $30 \%$ rock block proportion is characterized by suitable permeability and stability. At the same time, a certain rock block proportion for engineering can effectively reduce the construction costs.

(5) The roughness of the rock blocks can increase the friction between the soil and the rock and improve the stability of the soil-rock mixture. At the same time, reasonable gradation can make the soil-rock mixture form a more dense internal structure and reduce its permeability.

Permeability is an important index for evaluating the performance of water-blocking layer. In addition to the rock block proportions and hydraulic pressure, the shear failure caused by the uneven settlement of the dump site makes the shear resistance an important factor affecting the permeability. Rock block helps us to improve the shear resistance of the soil-rock mixture. Therefore, a comprehensive consideration of the effects of rock block grading and rock block proportions on the shear strength and permeability can provide a more comprehensive theoretical guidance for the stability of the water-blocking layer in an open-pit coal mine, and it is also the direction for further research.

\section{Data Availability}

The data used to support the findings of this study are included within the article.

\section{Conflicts of Interest}

The authors declare that there are no conflicts of interest regarding the publication of this article.

\section{Acknowledgments}

This study was supported by the Independent Research Project of State Key Laboratory of Coal Resources and Safe Mining, China University of Mining and Technology (SKLCRSM18X001).

\section{References}

[1] Y. Cao, J. Wang, Z. Bai et al., "Differentiation and mechanisms on physical properties of reconstructed soils on open-cast mine dump of loess area," Environmental Earth Sciences, vol. 74, no. 8, pp. 6367-6380, 2015.

[2] J. Wang, X. Li, Z. Bai, and L. Huang, "The effects of coal gangue and fly ash on the hydraulic properties and water content distribution in reconstructed soil profiles of coalmined land with a high groundwater table," Hydrological Processes, vol. 31, no. 3, pp. 687-697, 2017.
[3] X. Shi, W. Zhou, Q. Cai, and X. Lu, "Experimental study on nonlinear seepage characteristics and particle size gradation effect of fractured sandstones," Advances Civil Engineering, vol. 9, pp. 1-11, 2018.

[4] E. W. Medley, "Increases in slope stability of rock/soil mixtures due to tortuosity of failure surfaces around rock blocks," Abstracts with Programs-Geological Society of America, vol. 35, no. 6, p. $42,2003$.

[5] C. Mata, L. D. N. Guimarães, A. Ledesma, A. Gens, and S. Olivella, "A hydro-geochemical analysis of the saturation process with salt water of a bentonite crushed granite rock mixture in an engineered nuclear barrier," Engineering Geology, vol. 81, no. 3, pp. 227-245, 2005.

[6] B. Luczak-Wilamowska, "Mieszanki gruntowe w konstrukcjach skladowisk odpadow," Przeglad Geologiczny, vol. 58, no. 9/2, pp. 898-902, 2010.

[7] Y. Wei, Y. Yang, and M. Tao, "Effects of gravel content and particle size on abrasivity of sandy gravel mixtures," Engineering Geology, vol. 243, pp. 26-35, 2018.

[8] N. Coli, P. Berry, and D. Boldini, "In situ non-conventional shear tests for the mechanical characterisation of a bimrock," International Journal of Rock Mechanics and Mining Sciences, vol. 48, no. 1, pp. 95-102, 2011.

[9] X. Ding, X. Shi, W. Zhou, and B. Luan, "Experimental study on the permeability of a soil-rock mixture based on the threshold control method," Advances in Civil Engineering, vol. 2019, Article ID 8987052, 10 pages, 2019.

[10] N. Zhao, Y. Wang, B. Meng, and N. Luo, "Numerical simulation on the seepage properties of soil-rock mixture," Advances in Materials Science and Engineering, vol. 2018, Article ID 1859319, 10 pages, 2018.

[11] Z. Zhou, H. Yang, X. Wang, and B. Liu, "Model development and experimental verification for permeability coefficient of soil-rock mixture," International Journal of Geomechanics, vol. 17, no. 4, Article ID 04016106, 2017.

[12] S. Wang, W. Zhu, K. Fei, C. Xu, and N. Zhang, "Study on nondarcian flow sand-clay mixtures," Applied Clay Science, vol. 151, pp. 102-108, 2018.

[13] J.-J. Wang, S.-Y. Huang, Y.-M. Wen, Y. Yang, and M.-W. Liu, "Experimental study on interaction between compressibility and permeability of a crushed sandstone-mudstone particle mixture," Marine Georesources \& Geotechnology, vol. 35, no. 5, pp. 670-677, 2017

[14] T. Wang, S. Liu, Y. Feng et al., "Compaction characteristics and minimum void ratio prediction model for gap-graded soil-rock mixture," Applied Sciences, vol. 8, no. 12, 2018.

[15] T. Wan-Jun, C. Qing-Xiang, Z. Wei et al., "Study on technical index of pavement curing agent based on experiment of truck on ground," Coal Technology, vol. 36, no. 12, pp. 303-305, 2017.

[16] Y. Wang, X. Li, B. Zheng et al., "Experimental study on the non-darcy flow characteristics of soil-rock mixture," Environmental Earth Sciences, vol. 75, no. 9, 2016.

[17] S. Hui, L. Xian-Qi, B. I. Jin-Feng et al., "Numerical simulation of internal erosion characteristics of block in matrix soil aggregate," Rock and Soil Mechanics, vol. 38, no. 5, pp. 1497-1502, 2017.

[18] X. U. Yang, G. Qian, L. I. Xin et al., "In-situ experimental study of permeability of rock and soil aggregates," Rock and Soil Mechanics, vol. 30, no. 3, pp. 855-858, 2009.

[19] T. Chen, Y. Yang, H. Zheng, and Z. Wu, "Numerical determination of the effective permeability coefficient of soil-rock mixtures using the numerical manifold method," International Journal for Numerical and Analytical Methods in Geomechanics, vol. 43, no. 1, pp. 381-414, 2018. 
[20] W. Xu and Y. Wang, "Meso-structural permeability of S-RM based on numerical tests," Yantu Gongcheng Xuebao/Chinese Journal of Geotechnical Engineering, vol. 32, no. 4, pp. 542$550,2010$.

[21] X.-B. Chen, Z.-Y. Li, and J.-S. Zhang, "Effect of granite gravel content on improved granular mixtures as railway subgrade fillings," Journal of Central South University, vol. 21, no. 8, pp. 3361-3369, 2014.

[22] D. Ma, M. Rezania, H.-S. Yu, and H.-B. Bai, "Variations of hydraulic properties of granular sandstones during water inrush: effect of small particle migration," Engineering Geology, vol. 217, pp. 61-70, 2017. 